\title{
REFORMA DAS LEIS TRABALHISTAS E EDUCAÇÃO BÁSICA NA VISÃO DA CONFEDERAÇÃO NACIONAL DA INDÚSTRIA
}

\author{
LABOR LAWS REFORM AND BASIC EDUCATION IN THE VIEW OF \\ CONFEDERAÇÃO NACIONAL DA INDÚSTRIA (NATIONAL FEDERATION \\ OF INDUSTRY)
}

\begin{abstract}
Alessandro de Melo*
RESUMO

Este texto objetiva analisar a proposta do empresariado brasileiro sobre a reforma trabalhista, em que se defende a simplificação e a flexibilização como categorias norteadoras da relação capital-trabalho. Por simplificação, entendase que os empresários defendem uma legislação mais simples - o Simples Trabalhista, que desoneraria a produção dos "gastos" com os trabalhadores. Por flexibilização, os empresários reivindicam condições de negociação individual e flexibilidades relativas à jornada de trabalho e aos pagamentos de benefícios. Para a classe trabalhadora, essa reforma significaria um retrocesso da rede de direitos conquistados ao longo do século XX e materializados na CLT, embora, claramente, essa legislação possua elementos patentes de alteração, mesmo sob o ponto de vista dos trabalhadores. Tal reforma trabalhista não faria nada mais que radicalizar as condições já precárias do mundo do trabalho, trazendo insegurança e instabilidade para os trabalhadores. Em meio a propostas como essa, os empresários se propõem a discutir educação, baseando-se na proposta de centralidade da educação básica como foco do investimento público e como fonte de formação dos trabalhadores. No entanto, a proposta de qualidade em educação, advinda do empresariado, entra em contradição com as propostas da reforma trabalhista proclamada pelos próprios empresários. Que qualidade se espera para um trabalho precário? Que educação se faz necessária para um mundo do trabalho baseado no subemprego, na informalidade ou na instabilidade?
\end{abstract}

Palavras-chave: Confederação Nacional da Indústria. Reforma das Leis Trabalhistas. Educação Básica.

\begin{abstract}
This text aims to analyze the proposal of the Brazilian business about the labor reform, in which defend the simplification and the flexibility as categories guiding the relationship between capital-labor. For simplifying it is understood that the entrepreneurs advocate a law more simple - the Simple Labor, which would reduce the cost of production and "expenses" with the workers. For easing the entrepreneurs are demanding conditions of individual negotiation and flexibilities for working day and benefit payments. For the working class, this reform would mean a step backwards the network of rights won throughout
\end{abstract}

\footnotetext{
" Professor Adjunto do Departamento de Pedagogia da Universidade Estadual do Centro-Oeste, Campus Santa Cruz, Guarapuava-PR. Email: alessandrodemelo2006@hotmail.com
} 
the twentieth century, and materialized in CLT, although clearly, this legislation has elements patents amendment, even from the point of view of workers. This labor reform there would do nothing more than radicalize the already precarious conditions of the working world, bringing insecurity and instability for the workers. Amid proposals such as this labor reform, the entrepreneurs proposes to discuss education, based on a proposal to the centrality of basic education as a focus of public investment and as a source of training of workers, specially focused on the quality and skills training, based on the pillars of entrepreneurship and employability. However, the proposal of quality in education, from business, in contradiction with the proposals of labor reform by themselves proclaimed. What quality for a precarious work? What education for a world of work based on underemployment in informality or instability?

Key Words: National Confederation of Industry. Labor Laws Reform. Basic Education.

\section{Introdução}

O propósito deste texto é o de confrontar o posicionamento do empresariado brasileiro, reunido na Confederação Nacional da Indústria - CNI, em relação à reforma trabalhista como limite real das ideias de inclusão, qualidade e democracia do seu discurso educacional. Trata-se das conclusões de uma parte da tese de doutorado, a qual busca explicitar o projeto de educação básica do empresariado brasileiro a partir dos anos 2000 .

O empresariado brasileiro propõe uma radical reforma trabalhista, defendendo que o modelo atual de regulação das relações trabalhistas encontra-se defasado pelos avanços técnicos e de gestão do trabalho na contemporaneidade. No âmbito dessa reforma, os empresários defendem a simplificação e a flexibilização como categorias norteadoras da relação capital-trabalho. Por simplificação, entenda-se que os empresários defendem uma legislação mais simples - o Simples Trabalhista, que desoneraria a produção dos "gastos" com os trabalhadores. Por flexibilização, os empresários reivindicam condições de negociação individual e flexibilidades relativas à jornada de trabalho e pagamentos de benefícios. Para a classe trabalhadora, essa reforma significaria um retrocesso da rede de direitos conquistados ao longo do século XX e materializados na CLT, embora, claramente, tal legislação possua elementos patentes de alteração, mesmo sob o ponto de vista dos trabalhadores. Essa reforma trabalhista não faria nada mais que radicalizar as condições já precárias do mundo do trabalho, trazendo insegurança e instabilidade para os trabalhadores. Em meio a propostas como essa da reforma trabalhista, os empresários se propõem a discutir educação, baseando-se na proposta de centralidade da educação básica como foco do investimento público e como fonte de formação dos trabalhadores, especialmente focada na qualidade e na formação de competências, baseada nos pilares do empreendedorismo e da empregabilidade. No entanto, a proposta de qualidade em educação, advinda do empresariado, entra em contradição com as propostas de reforma trabalhista proclamada pelos próprios empresários.

Propõe-se, em primeiro lugar, levantar as pautas do empresariado e do governo Lula para a reforma trabalhista; em seguida, pretende-se mostrar dados do mundo do trabalho brasileiro. Por fim, com base nesses dados, será possível realizar a crítica da proposta da CNI demonstrando a sua faceta ideológica, no sentido dado por Marx e Engels em A ideologia alemã (1984). O ponto de partida aqui já foi dado no item 4.1 deste trabalho, em que apontamos o conjunto de leis aprovadas ao longo do governo $\mathrm{FHC}$ e que deram início às reformas no direito do trabalho na década de 1990 , no sentido de sua precarização.

Para alcançar o primeiro objetivo traçado acima será utilizado o documento Conclusões do $3^{\circ}$ Encontro Nacional da Indústria 2008 (CNI, 2008)',

\footnotetext{
${ }^{1}$ Além do documento citado, utilizaremos como subsídio os trabalhos de Saísse (2005) e da CNI (2009c) para o caso da terceirização.
} 
em que os empresários brasileiros, após o maior evento realizado pela indústria anualmente, proferem extenso panorama e recomendações ao Estado brasileiro sobre diversos temas, como tributação, inserção internacional da economia brasileira, infraestrutura, inovação e produtividade da indústria e meio ambiente.

Dados os limites do tema deste trabalho, será analisado o tópico dedicado ao Sistema trabalhista e impactos na competitividade industrial, o qual é dividido em cinco partes, assim designadas: terceirização; despesas de contratação; conflito e insegurança jurídica nas relações do trabalho; rotatividade; e questões de saúde e segurança do trabalho (idem).

\section{CNI, relações de trabalho e a reforma trabalhista}

O marco fundante do discurso da CNI sobre as relações de trabalho é que essas relações se tornaram defasadas frente às mudanças ocorridas no mundo da produção. Por um lado, as mudanças na base técnica e no nível da competitividade da indústria em termos mundiais exigem, do ponto de vista empresarial, que as relações trabalhistas sejam flexíveis e que a resolução de problemas entre as partes envolvidas nessa relação capital e trabalho seja efetivada no âmbito interno das empresas; ou, no máximo, em sistemas mediadores públicos que intentem a negociação, evitando conflitos de ordem trabalhista. Por outro lado, reclamam os industriais, as relações trabalhistas no Brasil sofrem do seu mal de origem, ou seja, de uma legislação trabalhista baseada na ação de um Estado paternalista, o qual proporciona mecanismos que seriam exagerados na defesa dos trabalhadores. Dessa forma, o Estado torna excessivamente dispendiosa a contratação regular de mão-de-obra, além de ser um sistema rígido e que está centrado na lógica do conflito entre capital e trabalho, algo que a CNI procura negar. O resultado desse tipo de relações trabalhistas, segundo a ótica do empresariado, é o enorme contingente de desempregados, ou de trabalhadores vinculados informalmente no mundo do trabalho. Saisse (2005) coloca os problemas relativos à regulação do trabalho, e a crítica da CLT, da seguinte forma:

Todos os aspectos das relações de trabalho são contemplados: fixação do salário, condições de trabalho, contratação e demissão. Trabalhadores e empregadores não podem negociar, por exemplo, tempo de férias, aviso prévio ou o pagamento do $13^{\circ}$ salário, mesmo que isso interesse a ambas as partes para evitar alternativa pior. A lei desce a detalhes como impedir que trabalhadores com mais de 50 anos dividam em dois o período de férias a que têm direito (Art.134, $\S 2^{\circ}$ da CLT).

A lei retira dos trabalhadores e empregadores a capacidade de decidirem o que é melhor para eles. Desse modo, desestimula a negociação e convida ao litígio. Quando as negociações acontecem, suas disposições podem ser contestadas nos tribunais (que, no Brasil, têm o poder não apenas de arbitrar, mas também de fixar normas), mesmo quando resultantes do entendimento entre as partes diretamente envolvidas. O quadro legal impõe ao custo de contratação mais de $100 \%$ do salário direto sob a forma de encargos compulsórios e inegociáveis. (SAISSE, 2005, p.06).

A crítica efetuada pela autora do relatório técnico encomendado pela CNI, e que de fato é a reprodução do pensamento dos empresários brasileiros, é que a legislação trabalhista é rígida justamente pelo fato de prever, ou assim pretender, todas as situações possíveis na relação entre capital e trabalho. Isso, no entendimento da autora, impossibilita o livre diálogo e acordos mais flexíveis entre as partes, além de colocar o Estado como mediador.

A lógica da reforma trabalhista, portanto, é atacar o cerne rígido das relações de trabalho existentes no país e, para isso, tem na pauta presente nas Conclusões (CNI, 2008) os pontos a serem atacados.

Antes de entrar nos destaques da reforma, como a terceirização, custos e flexibilização dos contratos, podemos destacar do texto de Saisse (2005) outros elementos que subsidiam a crítica dos empresários à regulação das relações de trabalho e as propostas para a superação de sua rigidez e atraso. A autora, em seu relatório técnico, destaca que o Banco Mundial realizou, em 2004, uma pesquisa no mundo inteiro visando a verificar o ambiente regulatório do trabalho em 145 países $^{2}$. Uma parte dos resultados é assim descrita pela autora:

Para o conjunto de 145 países considerados no levantamento, o Brasil fica em $26^{\circ}$ lugar (junto a

2 Trata-se do "World Development Report 2005: a better investment climate for everyone. Washington, DC: World Bank and Oxford University Press, 2004". 
outros 5 países) dentre aqueles onde é mais difícil contratar, em $13^{\circ}$ lugar (com outros 12) dentre os países onde as empresas têm mais dificuldades para demitir e em $12^{\circ}$ lugar (junto com o México) dentre os de regulação do mercado de trabalho mais rígida. (idem, p. 07).

Os pontos que levaram o Brasil a essa posição são listados a seguir:

Os contratos por prazo determinado podem ser aplicados apenas para trabalhos temporários.

O prazo máximo legal de duração desses contratos é inferior a três anos (o Art.445 estipula o prazo máximo de dois anos).

Há restrições ao trabalho noturno, que é remunerado $20 \%$ acima do diurno;

Há várias restrições ao trabalho aos domingos;

$\mathrm{O}$ dia de trabalho, incluindo as horas extras, não chega a 12 horas (é de, no máximo, 10, segundo os Art. 58 e 59);

As férias anuais pagas são superiores a 21 dias (o Art. 130 fixa em 30 dias corridos);

Toda demissão precisa ser notificada;

A redundância não é considerada causa justa para demissão;

Toda demissão sem justa causa implica pagamento de multa pela empresa. (idem).

A listagem desses itens é interessante para observarmos que os critérios adotados mundialmente para avaliar a rigidez do marco regulatório do trabalho, e, simultaneamente, para subsidiar os argumentos em favor da reforma trabalhista, parecem apontar para algo importante no que se refere ao posicionamento dos empresários: se são esses os fatores que levam o Brasil a ser rígido na manutenção da regulação do trabalho, ao mesmo tempo são esses os fatores que garantem aos trabalhadores um mínimo de dignidade no trabalho. Logo, a manifestação da necessidade de flexibilizar esses itens, ou mesmo de romper definitivamente com os mesmos, leva, do nosso ponto de vista, ao entendimento de que o objetivo dos empresários é a perpetuação de um trabalho precário. Portanto, isso é de fato um limite às boas intenções disparadas em seus discursos sobre educação de qualidade, formação dos trabalhadores etc.

Prosseguindo nos seus argumentos em favor da reforma, a autora coloca como diretriz básica para que essa reforma seja envidada com sucesso a redução dos custos do trabalho formal para as empresas; ou seja, de fato não é mascarado pelo empresariado que o objetivo das reformas é reduzir o custo com mão-de-obra e, com isso, aumentar a apropriação do resultado do trabalho. Não se pode esquecer que, somadas a esse mecanismo, existem atualmente várias formas de exploração da mais-valia relativa e absoluta: incremento de tecnologia; intensificação do trabalho, com a redução de trabalhadores; aumento da jornada de trabalho (inclusive aos domingos); redução de salários; banco de horas, entre outras.

Dentre as pautas que parecem ser mais relevantes no último período destaca-se a terceirização, que é o tema do Projeto de Lei - PL 4302/1998, que está há onze anos tramitando no Congresso sem ser aprovado. A ação da CNI junto ao Congresso é pela defesa da terceirização tanto das atividades- meio quanto das atividades-fim da empresa (CNI, 2009). Ou seja, a CNI propõe a possibilidade de flexibilizar as relações trabalhistas em todo o âmbito da empresa, o que hoje é permitido apenas para atividades-meio, ou seja, para aquelas atividades que não constituem o objetivo primeiro da empresa ${ }^{3}$.

A terceirização é entendida pela CNI como sendo a "[...] contratação de serviços e não de recursos humanos" (CNI, 2008, p.55), diferenciando-se, portanto, da intermediação de mão-de-obra. Esse tipo de contratação, segundo a CNI, gera maior eficiência e empregos por ser mais rápido e barato, além de reduzir a carga dos tributos trabalhistas das empresas, que repassam essa incumbência para as empresas terceirizadoras. A questão posta pela CNI é a necessidade de regulamentar tal forma de contratação, dando "[...] proteção aos trabalhadores e segurança jurídica para as empresas". (idem). Entretanto, no próprio âmbito da CNI (CNI, 2009c), o viés principal da terceirização é a redução de custos, como pode se constatar a seguir:

Os empresários que terceirizam foram solicitados a definir o grau de importância de três possíveis razões para a terceirização: aumento da qualidade do serviço, redução de custos e uso de novas tecnologias de produção ou gestão. Dentre as opções apresentadas, a redução de custos apresenta-se

\footnotetext{
${ }^{3}$ Ver Lei 6019, de 03/01/1974; Súmula TST n. 331. Na verdade, embora haja na lei a diferenciação entre atividades-meio e atividades-fim de uma empresa, estas não estão completamente definidas, gerando discussões, resoluções e jurisprudências variadas
} 
como o principal motivo para a decisão de terceirizar. $47 \%$ dos empresários consideram essa opção muito importante e $44 \%$ importante. Apenas $9 \%$ a considera não importante. (idem, p.03).

Além disso, a literatura crítica (ALVES, 2000; 2007; ANTUNES, 2005; MARCELINO, 2006) e os movimentos dos trabalhadores indicam que a terceirização, na verdade, acaba por ocasionar problemas de várias ordens no seio da classe trabalhadora brasileira e mundial (para o caso da França, MARCELINO, 2006). Um dos problemas é a degradação salarial dos trabalhadores terceirizados. Esse fato é inequívoco, pois é da própria natureza do processo de terceirização - surgido no âmbito da reestruturação produtiva a partir dos anos de 1970, sob a hegemonia do toyotismo - que as empresas terceirizadas devem se mostrar como alternativas viáveis (mais baratas) para as empresas que as contratam, havendo nessa transação, portanto, vantagens competitivas. O foco principal da terceirização, do ponto de vista das empresas contratantes dos serviços terceirizados, é justamente o fato de que essas empresas contratam mão-de-obra mais barata, recaindo esse barateamento em cascata para a empresa principal, que, com isso, além de economizar nos custos administrativos inerentes à contratação direta, economiza também com pagamentos menores devidos a cada trabalhador.

Tal estratégia constitui-se, de fato, em uma das principais características do toyotismo no que se refere ao reposicionamento do capital para a acumulação em tempos de crise estrutural do capitalismo. Todo o ônus da operação de contratação é terceirizado para outras empresas, e, no fim das contas, é a classe trabalhadora, cada vez mais precarizada, que acaba por pagar essa conta.

Mas a terceirização constitui-se, também, em mecanismo de dominação de classe adaptada aos tempos de desemprego estrutural e alta competitividade capitalista. A terceirização causa uma divisão entre os trabalhadores que são contratados pela empresa principal e aqueles contratados pelas terceirizadas. Essa divisão ocorre pela diferença salarial e pela forma de contratação.

A Sondagem da CNI (2009c) mostra ainda outra problemática, que é a diferenciação entre as terceirizações que ocorrem nas micro e pequenas empresas e nas grandes empresas. Apesar de afirmar que a grande maioria das empresas de todos os portes se assegura dos direitos trabalhistas de seus terceirizados, um dado demonstra que a situação é grave para os trabalhadores terceirizados nas micro e pequenas empresas, pois apenas $51 \%$ delas direciona o mesmo tratamento aos terceirizados e aos efetivos (idem, p. 07).

Em decorrência disso, a divisão interna na classe trabalhadora tende, e de fato isso ocorre, a desmobilizar boa parte da mão-de-obra, que, pressionada pelo desemprego e pelo precário vínculo terceirizado, não busca a luta orgânica como classe para alcançar as suas demandas. Assim, a terceirização, além de ser uma economia de gastos com a força de trabalho, é também mecanismo de manipulação e de hegemonia da classe dominante.

A terceirização é, também, um mecanismo de ampliação da produtividade e competitividade das empresas. Estas, despreocupadas com parte da carga trabalhista e tudo o que dela deriva, passam a se concentrar no foco principal, podendo investir mais recursos, por exemplo, em inovação, que é um fator de fundamental importância para a competitividade.

Dessa forma, conclui-se que o processo de terceirização defendido pela CNI, embora apareça revestido de uma preocupação com a proteção dos trabalhadores, na verdade é um fator de desintegração de classe, de precarização e flexibilização das relações trabalhistas no país.

O próximo item da pauta das relações de trabalho da CNI vincula-se aos custos com contratação de força de trabalho. Para a entidade, o custo de contratação no país é muito elevado, e a legislação pertinente é complexa e gera distorções de entendimento. Além disso, a legislação atual não permite a contratação de trabalhadores como pessoa jurídica, trabalho cooperado, trabalho por tarefa (CNI, 2008).

Perante essas demandas, a CNI recomenda ao governo a redução nos gastos da folha de pagamentos, especialmente para as pequenas e micro empresas, criando um "Simples Trabalhista", semelhante ao Simples Nacional, forma simplificada de tributação para esses tipos de empresas.

A CNI, ao defender a flexibilização das formas de contratação de trabalhadores, inclusive como cooperados, por tarefa ou como pessoa jurídica, abre mais brechas para a fragmentação da classe 
trabalhadora, além de demonstrar claramente que a competitividade industrial em pleno capitalismo no século XXI, convive harmoniosamente com formas de relações trabalhistas antigas, como o trabalho por tarefa. Tal forma de contratação cria um vínculo precário entre empresas e trabalhadores, dando àquelas os bônus de um trabalhador dedicado a uma tarefa específica, remunerado conforme o cumprimento de tarefas e a sua agilidade nesse cumprimento.

Com relação ao trabalho cooperado, este é resultado de um contrato entre uma empresa e uma cooperativa de trabalhadores para o cumprimento de tarefas específicas por tempo determinado. Nesse caso, por tratar-se de trabalhadores cooperados, a empresa não necessita pagar as contribuições trabalhistas, como o Fundo de Garantia por Tempo de Serviço - FGTS, a multa de $40 \%$ do FGTS em caso de demissão, entre outros encargos sociais para com os trabalhadores. A contratação de uma cooperativa de trabalho não deixa de ter, para as empresas, as vantagens do processo de terceirização; todavia, para a classe trabalhadora, constitui um engodo.

O terceiro item da pauta da CNI é a questão do conflito e da insegurança jurídica nas relações de trabalho. Os empresários, baseados na CLT, afirmam que a legislação trabalhista no país estimula o conflito entre capital e trabalho, aumentando as despesas das empresas. Além disso, a CLT é acusada de não acompanhar "[...] o avanço dos processos produtivos e a dinâmica tecnológica, fazendo com que os novos modelos de organização da produção sujeitem as empresas à insegurança jurídica e os trabalhadores à falta de proteção." (CNI, 2008, p. 56).

As recomendações da CNI giram em torno da simplificação da legislação trabalhista, eliminando possíveis ambiguidades e distorções: evitar a todo custo o papel do Judiciário como legislador de causas trabalhistas; propor uma atuação educativa do fiscal do trabalho, ao invés de uma atuação punitiva; "aperfeiçoar" a legislação, para permitir novas formas de contratação; estimular o acordo entre capital e trabalho; ampliar as possibilidades da negociação coletiva, de forma que esta possa se sobrepor à lei; criar e implementar Comissões de Conciliação Prévia - CCP; regulamentar a contratação de aprendizes; incentivar a inclusão de deficientes, com políticas de incentivos e formação profissional entre outras.
Os itens acima enumerados, em conjunto, perfazem o caminho até aqui apontado de flexibilização das relações de trabalho, mas de uma forma a aparecer para a sociedade como demandas genéricas, com alto poder de sedução sobre o senso comum e a opinião pública. Tanto é assim que podemos ver na grande imprensa um consenso a respeito da necessidade de melhoramento das leis trabalhistas, a crítica à rigidez caracterizadora da CLT, o vínculo entre aumento do emprego e redução dos encargos sociais etc.

Claro está que a simplificação da legislação é uma demanda não apenas do empresariado, mas de todos os trabalhadores; afinal de contas, as ambiguidades nas interpretações da lei podem favorecer o capital. Uma legislação clara, portanto, é uma reivindicação sobre a qual existe um consenso, mas não se pode afirmar o mesmo em relação ao conteúdo da legislação trabalhista. Para o capital interessa realizar pressão aberta para que tal legislação favoreça a economia de gastos com os trabalhadores, inclusive com formas particulares de arrocho salarial, como o caso das terceirizações. Por outro lado, para a classe trabalhadora o interesse imediato é obter melhores salários e melhores condições de trabalho, com certa segurança.

É interessante notar que, no caso das recomendações acima mencionadas, os empresários enfatizam a necessidade de se evitar conflitos entre capital e trabalho, porém insistem em priorizar reformas de cunho precarizador das condições de trabalho. Ou seja, constitui-se, essa demanda, como verdadeira imposição de uma visão de mundo burguesa, no interior da qual a classe trabalhadora deve apenas se adaptar.

A ênfase na conciliação prévia (dentro da empresa, antes de se dirigir ao Poder Judiciário) nada mais significa, ideologicamente, que apontar a relação entre capital e trabalho como uma relação de fato entre iguais. Esse tipo de relação não pode ser entendido, a não ser por um mecanismo ideológico, no sentido de falseamento da realidade concreta, em que há uma hegemonia da burguesia sobre a classe trabalhadora.

O quarto item das Conclusões denomina-se "Rotatividade", e é assim enunciado no documento: "A combinação das regras do FGTS com as do seguro-desemprego tem induzido à elevação da rotatividade. 
Isso tem gerado perda de produtividade e despesas para as empresas e para o erário público." (CNI, 2008, p. 58).

$\mathrm{Na}$ verdade, a CNI quer nos fazer crer que a rotatividade dos trabalhadores é causada pela existência de uma rede de seguridade social, FGTS e Seguro Desemprego que estimula os trabalhadores a saírem do emprego constantemente. Ao sacramentar tal discurso, falseando o entendimento da concretude das relações sociais e de trabalho, a CNI não esconde seu viés ideológico.

A rotatividade dos trabalhadores gera, realmente, um custo para as empresas, por estas terem como obrigação o pagamento dos encargos sociais devidos a essa rotatividade e à contratação de pessoal para substituição. No entanto, é contestável afirmar que a motivação da rotatividade é devida ao fato de o trabalhador encontrar, fora do emprego, um sistema de seguridade que o ampare.

Uma análise minimamente coerente afirma (IEDI, 2005), do ponto de vista empresarial, que o fluxo de pessoal na indústria atende a ciclos econômicos: em um período de aquecimento da atividade industrial, percebe-se um maior movimento nas demissões voluntárias dos trabalhadores, os quais almejam melhores colocações na indústria. Em épocas de crise, ao contrário, esse tipo de demissões diminui consideravelmente, ao passo que as demissões por parte das empresas crescem.

Outra característica da rotatividade, apontada pelo IEDI (idem), é que esta é maior nos setores de produtividade sazonal e nos setores que exigem menor qualificação da mão-de-obra, sendo possível, portanto, desfazer-se dela e encontrar facilmente substituição no mercado de trabalho. "Inversamente, os setores mais modernos tecnologicamente tendem a ter menor rotatividade, pois empregam mão-de-obra mais qualificada, pagam melhores salários e oferecem um atrativo mercado de trabalho interno a seus empregados." (idem) Em termos regionais, aponta o IEDI, as regiões Norte e Sul despontam com maiores taxas de rotatividade, a primeira pela sua condição de atraso tecnológico, e a segunda pela presença da agroindústria, caracteristicamente sazonal (idem).

$\mathrm{Na}$ verdade, a proposta dos empresários sobre rotatividade centra-se na questão de uma melhor regulação do pagamento do seguro-desemprego, tendo como proposta a vinculação desse seguro a um processo de qualificação dos trabalhadores. A proposta da CNI também se refere a mudanças no aviso-prévio, proporcional ao tempo de empresa, limitado a 30 dias (atualmente, esse aviso-prévio é, indistintamente, de 30 dias ou a critério de uma negociação entre trabalhador e empregador). A revisão do pagamento da multa de $40 \%$ do FGTS em caso de demissão é outro alvo dos empresários. Nas propostas de reforma trabalhista essa multa sempre foi um ponto nevrálgico que contrapôs trabalhadores e empresários. A proposta aqui é a flexibilização do pagamento de tal multa, tendo em vista a proporcionalidade em relação ao tempo de serviço na empresa e a extinção do adicional de $10 \%$ atualmente existente (CNI, 2008).

$\mathrm{O}$ último item da pauta da CNI refere-se à gestão da saúde e segurança do trabalho - SST. Nesse item, a crítica dos empresários é quanto à complexidade e dubiedade da legislação referente ao tema, que causa insegurança para os empresários e trabalhadores. A proteção ao trabalhador, que, na visão da CNI, deveria ser o objetivo último das políticas de SST, passa a ser substituída por um modelo punitivo para os empresários (CNI, 2008). Sendo assim, as recomendações remetem ao aprimoramento da comunicação das leis de SST, tanto para empresários quanto para os trabalhadores; à simplificação das Normas Regulamentadoras; à implementação de uma cultura da educação e não da punição, como é hoje; e à criação de políticas para a redução dos custos com SST, entre outras.

Aqui, há de se compreender que a insistência do empresariado em substituir a "cultura da punição" pela educação (como querem que seja a fiscalização do trabalho), nada mais é que a expressão da vontade da classe burguesa de que as mediações das relações trabalhistas saiam da esfera de ação estatal e figurem como expressões das relações privadas entre capital e trabalho. Desse modo, tais relações seriam mais vantajosas para o capital, haja vista o processo histórico de dominação de classe no capitalismo.

Além desses itens constantes no documento final do ENAI de 2008, existem na pauta dessa entidade outros dois que também aparecem no CNI em Ação, Edição Especial de dezembro de 2009 (CNI, 2009a): a questão da dispensa imotivada e a redução da jornada de trabalho. 
A dispensa imotivada é tema do Projeto de Lei Complementar proposto desde 18 de fevereiro de 2003 pelo deputado do Partido dos Trabalhadores de Pernambuco - PT/PE, Maurício Rands ${ }^{4}$. Esse projeto encontra-se, atualmente, pronto para entrar na Pauta da Comissão de Trabalho, Administração e Serviços Públicos - CTASP, sendo que já foi rejeitado na Comissão de Desenvolvimento Econômico, Indústria e Comércio - CDEIC $^{5}$. Trata-se de garantir o que consta no Inciso I do Art. 7 da Constituição Federal de 1988, que diz que são direitos dos trabalhadores, entre outros itens: "I - relação de emprego protegida contra despedida arbitrária ou sem justa causa, nos termos de lei complementar, que preverá indenização compensatória, dentre outros direitos". (BRASIL, 1988). Esse Inciso, como se lê, necessita de uma lei complementar para que possa vigorar, e é esse o objetivo do deputado petista.

Consta no projeto que a demissão do trabalhador somente poderá ser realizada por motivos objetivos e subjetivos devidamente esclarecidos pelo empregador. Como motivos objetivos o deputado aponta os motivados pelas questões de ordem econômica que atingem as empresas, como dificuldades econômicas e financeiras ou reestruturação produtiva; por motivos subjetivos se entende aqueles que se relacionam à indisciplina ou insuficiência de desempenho. Em caso de demissão sem que o empregador possa provar quaisquer dessas motivações para a justiça, o trabalhador poderá ser ressarcido de duas formas, à sua escolha: ou ser readmitido ou ser pago por meio de indenização, para cujo conteúdo o projeto é vago.

A posição da CNI é a de que esse projeto deve ser barrado por cercear a liberdade de empreendimento e gestão dos recursos humanos pelas empresas, inclusive, afirma a CNI, inviabilizando esses empreendimentos com muita rigidez e reduzindo o emprego formal. Além do mais, argumenta a CNI, os trabalhadores já contam com diversas leis que os protegem em caso de demissão imotivada, como o aviso prévio de 30 dias, férias, $13^{\circ}$ salário proporcional, multa de $40 \%$ do FGTS.

\footnotetext{
${ }^{4}$ Trata-se, na verdade, da ratificação da Convenção 158 da Organização Internacional do Trabalho $\square$ OIT, em relação à qual a CNI se posiciona contrária (CNI, 2008b).

${ }^{5}$ Para o levantamento dessas informações foi consultado o site da Câmara dos Deputados: www.camara.gov.br.
}

Claro está que tal proposta seria frontalmente atacada pelo empresariado, pois mexe em um dos núcleos da sua liberdade de ação, que é a gestão dos seus recursos humanos. No entanto, o referido projeto não se vincula à livre criação do deputado pernambucano, mas é um direito expresso na Constituição Federal de 1988, a qual, apesar de ter sido denominada de "Constituição cidadã" pelos políticos e movimentos sociais, foi rejeitada pela CNI. Tal rejeição aconteceu pelo fato de essa Constituição ser vista como "[...] importante fonte de desigualdade e exclusão sociais no Brasil" (CNI, 2002, p. 141), justamente pelas questões das relações de trabalho nela aprovadas.

Portanto, sem rodeios, podemos afirmar categoricamente que a CNI descarta como princípio que haja intervenções nas relações entre capital e trabalho no que tange à gestão dos recursos humanos, expressando, assim, a ideia de que a regulação das relações capital e trabalho deve ocorrer no âmbito da própria empresa, entre aqueles que, "livremente", assinam o contrato de trabalho como "iguais", embora com direitos e deveres diferenciados. Tal posição denota uma visão de mundo que defende essa paridade entre capital e trabalho, mistificando o que, na realidade, constituiu-se historicamente como uma relação de dominação.

Há de se discutir, do ponto de vista da classe trabalhadora, se essa manutenção do emprego pela burguesia, orientada por uma obrigação legal, constitui uma saída estratégica, do ponto de vista revolucionário.

Outra pauta da CNI refere-se à redução da jornada de trabalho de 44 horas semanais atuais para 40 horas semanais, e ao aumento da hora extra de $50 \%$ para $75 \%$, que é o conteúdo da Proposta de Emenda à Constituição - PEC 231/1995, da lavra do deputado Inácio Arruda, do Partido Comunista do Brasil do Ceará - PCdoB/CE. Sobre isso tratam dois documentos da CNI (CNI, 2009a; 2009d).

$\mathrm{O}$ argumento central dos empresários é que a aprovação de uma lei que trate desse tema não pode, por si mesma, gerar mais e melhores empregos, e que são os acordos entre as partes (capital e trabalho) que têm evitado a elevação do número de desempregos no país. "Eles indicam que a livre negociação é o caminho para a preservação das necessidades dos trabalhadores e das empresas." (CNI, 2009d, p. 02). 
Na verdade, o crescimento econômico é a alavanca para a geração de empregos. "Ou seja, a criação de empregos depende, basicamente, de investimentos na produção, crescimento econômico sustentado e garantia de educação básica e profissional de boa qualidade." (idem, p. 03).

Em outro documento (CNI, 2009a), está expressa a grande mobilização efetuada pelo empresariado, juntamente com os parlamentares, com o intuito de demonstrar que, do ponto de vista da classe empresarial, a redução da jornada poderia gerar o aumento dos custos com a mão-de-obra e, consequentemente, a redução dos empregos formais na indústria. Com esse entendimento, foi elaborada cartilha para as empresas, sindicatos e associações.

Ao longo da tramitação do projeto houve a criação de uma Comissão Especial para a análise da PEC 231, instituída em 08 de dezembro de 2008, cujo relator foi o deputado Vicentinho - PT-SP. Ao longo do ano de 2009, e com vistas a melhor executar seu relatório, esse deputado convidou representantes dos trabalhadores, deputados, juízes, representantes do empresariado, economistas, entre outros, que apontaram as positividades de uma eventual redução da jornada de trabalho para 40 horas semanais. Ao longo das jornadas de debate sobre a PEC 231, a grande maioria dos palestrantes foi de parecer favorável à redução da jornada, tendo como argumentos várias motivações, aqui sintetizadas: geração de empregos; redução da incidência de doenças e acidentes de trabalho; a produtividade alcançada pela indústria justificaria a redução da jornada sem prejuízo para o setor produtivo; a jornada média dos trabalhadores brasileiros já é próxima de 40 horas semanais, o que não traria grande impacto caso fosse aprovada a PEC 231; o caso dos trabalhadores do comércio, cuja jornada é muito superior a 44 horas semanais; a redução da jornada significaria o alcance de um novo patamar civilizatório para o país; a medida reduziria o uso e abuso das horas extras; a redução da jornada significaria melhorar as condições de cidadania, dando aos trabalhadores possibilidade de se dedicar mais a outras atividades familiares, sociais, culturais etc.

Por outro lado, aqueles que se posicionaram contrariamente à aprovação da PEC 231 argumentaram que a redução da jornada por si não garantiria o aumento dos empregos; que, ao invés dessa medida, o governo deveria simplificar a contratação de trabalhadores (o Simples Trabalhista); que a jornada de trabalho no Brasil já é menor que 44 horas semanais, e que essa questão deveria ser resolvida no âmbito das negociações coletivas. Houve, ainda, uma colocação interessante do representante do Instituto de Pesquisa Econômica Aplicada - IPEA, Roberto Henrique Gonzalez. Apesar de ser favorável à redução da jornada, Gonzalez considera que essa redução poderia gerar outro efeito sobre a classe trabalhadora: o aumento da intensidade do traba1ho. Ou seja, a cobrança da mesma produtividade em menor tempo de trabalho, o que classicamente significa maior exploração da mais-valia relativa ${ }^{6}$.

O Departamento Intersindical de Estatística e Estudos Socioeconômicos - DIEESE (DIEESE, 2007) apontou, em seu estudo, algumas condições que estão dadas atualmente na economia brasileira, que possibilitariam a redução da jornada sem redução de salários:

- a produtividade do trabalho mais que dobrou nos anos 90;

- o custo com salários é um dos mais baixos no mundo;

- o peso dos salários no custo total de produção é baixo;

- o processo de flexibilização da legislação trabalhista, ocorrido ao longo da década de 90 , intensificou, significativamente, o ritmo do trabalho. (DIEESE, 2007, p.03).

Para os empresários, porém, ao contrário da geração de novos empregos, a redução da jornada sem a redução de salários aumentará os custos de contratação e, com isso, as empresas deverão buscar alternativas, que assinalam: compra de máquinas para automação; redução da produção; e intensificação do trabalho no quadro de empregados existentes. (CNI, 2009d, p. 05). As microempresas e pequenas empresas sofrerão as maiores consequências se essa medida for implementada, e o impacto dessas consequências para os trabalhadores não seria desprezível, dado o alcance dessas empregadoras na geração de empregos.

Mas, ainda na contracorrente da argumentação empresarial, vemos que a redução da jornada de

\footnotetext{
${ }^{6}$ Tanto o deputado Vicentinho quanto a Comissão aprovaram a PEC 231.
} 
trabalho ocorreu ao longo do século XX no mundo inteiro, e no Brasil ela baixou de 48 horas semanais, estipulados na década de 30, para 44 horas semanais, na Constituição de 1988, devido a muitas lutas. Algumas categorias, como os metalúrgicos, devido à sua organização mais desenvolvida, alcançaram a jornada de 40 horas semanais. No entanto, segundo o DIEESE (idem), o capital vem revidando a essa conquista com alternativas de exploração da classe trabalhadora, como o incentivo à hora extra ${ }^{7}$, a intensificação da produtividade com a reestruturação produtiva, incrementos tecnológicos ou mesmo reduções de pausas na linha de produção. Outra forma é a flexibilização do tempo de trabalho, como, por exemplo, ocorre em épocas de crise econômica, em que os trabalhadores são chamados a trabalhar menos, ou a se afastar da produção; e em outros tempos, de aquecimento, em que são chamados a recompor o tempo parado com jornadas mais longas, para que a empresa possa atender às demandas da produção. Um exemplo disso é o chamado "banco de horas". "Por esse motivo, a luta pela redução da jornada abrange não só uma jornada menor, mas também a limitação da hora extra, bem como a revogação da lei sobre o banco de horas e o trabalho aos domingos." (DIEESE, 2007, p. 04) ${ }^{8}$

Outro item que tem repercutido nos fóruns de crítica à reforma trabalhista ${ }^{9}$, e também na pauta da $\mathrm{CNI}^{10}$, refere-se à implementação do chamado Super Simples Nacional, que institui o Estatuto Nacional

\footnotetext{
${ }^{7}$ Segundo o mesmo documento, são realizadas no país cerca de 52.800 .000 horas extras por semana (DIEESE, 2007, p. 06).

${ }^{8}$ Impressiona, ao vermos esta discussão, a atualidade do debate de Marx em O Capital (1998) sobre a jornada de trabalho.

${ }^{9}$ O FÓRUM-FISCO NACIONAL, que reúne a UNAFISCO-SINDICAL - Sindicato Nacional dos Auditores-Fiscais da Receita Federal, a ANFIP - Associação Nacional dos Fiscais da Previdência, a FENAFISCO Federação Nacional do Fisco Estadual, a FENAFIM - Federação Nacional dos Auditores e Fiscais de Tributos Municipais, a FEBRAFITE - Federação Brasileira de Associações de Fiscais de Tributos Estaduais, a FENAFISP - Federação Nacional dos Auditores-Fiscais da Previdência Social e o SINAIT - Sindicato Nacional dos Auditores-Fiscais do Trabalho constituise no maior articulador das críticas ao Projeto.

${ }^{10}$ Desde 2004 a CNI vem acompanhando no Congresso o desenrolar da PLP123. Neste ano a Agenda Legislativa traz a preocupação com o encaminhamento da lei, apoiando-a em geral, e apenas apresentando algumas questões relativas à definição de alíquotas e divisão da arrecadação entre os entes da federação. No link do site da CNI, denominado CNI EM $A C ̧ \tilde{A} O$ (www.cni.org.br), consta a entrada para a discussão da entidade sobre as micro e pequenas empresas e, especificamente, sobre o Estatuto Nacional das Micro e Pequenas Empresas. Neste são apresentadas as ações da CNI em 2007, ano em que efetivou discussões com o Congresso e com o empresariado em geral sobre a necessidade da legislação e a efetivação de pequenas mudanças no projeto. Em 2009 (CNI, 2009b) continua presente a preocupação da entidade com tal questão.
}

da Microempresa e da Empresa de Pequeno Porte, que está tramitando no Congresso Nacional (Projeto de Lei Complementar n. 123/2004).

Segundo consta na Seção II do referido projeto, intitulada Das Obrigações Trabalhistas (a qual constitui parte do Capítulo VI, intitulado Da Simplificação das Relações de Trabalho), uma série de direitos trabalhistas historicamente conquistados e já plenamente implementados são flexibilizados ou extintos para as microempresas e pequenas empresas. Para não restar dúvidas, trazemos para o debate o Art. 51 desse projeto:

\section{Seção II}

Das Obrigações Trabalhistas

Art. 51. As microempresas e as empresas de pequeno porte são dispensadas:

I - da afixação de Quadro de Trabalho em suas dependências;

II - da anotação das férias dos empregados nos respectivos livros ou fichas de registro;

III - de empregar e matricular seus aprendizes nos cursos dos Serviços Nacionais de Aprendizagem;

IV - da posse do livro intitulado "Inspeção do Trabalho"; e

$\mathrm{V}$ - de comunicar ao Ministério do Trabalho e Emprego a concessão de férias coletivas. (Disponível no site: http://www.camara.gov.br/sileg/integras/427877.pdf. Acesso em 12 jan. 2010).

Como 95\% das empresas constituídas no Brasil são microempresas e empregam cerca de 50\% da força de trabalho brasileira (PASTORE, 2005), percebe-se por aí o alcance de tais medidas para a classe trabalhadora. Em termos de flexibilidade das relações trabalhistas, essas medidas contemplam plenamente as demandas da CNI, pois eliminam boa parte da burocracia e dos custos envolvidos na contratação e demissão de mão-de-obra.

No entanto, no que se refere aos trabalhadores, essa legislação deteriora ainda mais as condições de trabalho, reduzindo garantias e mesmo elementos de composição salarial. Sobre isso, a leitura do Art. 51 do PLP fala por si mesma. Mas, além das perdas de direitos de $50 \%$ da força de trabalho brasileira, a PLP ainda traz como prejuízo para a sociedade a precarização da fiscalização trabalhista, que pode garantir direitos aos trabalhadores e, por outro lado, punir a má conduta, omissão ou mesmo 
crimes patronais em relação aos direitos trabalhistas, previdenciários e relativos à SST. Os itens do Art. 51 demonstram a fragilidade do próprio Estado em fiscalizar as empresas, já que estas não são mais obrigadas a apresentar uma série de documentos que garantem uma boa qualidade no trabalho. Ao não exigir a documentação de forma ostensiva, o Estado abre brecha para que as empresas não cumpram deveres para com o trabalhador, reduzindo as relações trabalhistas a confrontos pessoais (lembramos que a média de trabalhadores dessas micro e pequenas empresas é de um a quatro funcionários), nos quais o empresário, devido à sua posição na relação de forças, pode oprimir o trabalhador com a ameaça do desemprego e deixar de cumprir aquilo que a própria lei flexibiliza. Até mesmo direitos históricos como o $13^{\circ}$ salário, pagamento de férias, entre outros, podem ser descumpridos, já que a fiscalização não mais teria poder efetivo de punição.

O Art. 53 traz, ainda, outras formas de flexibilizar e melhorar a condição do empresário, dispensando-o de pagamentos de contribuições sociais determinadas, por exemplo, na Lei Complementar n. 101, de 29 de junho de 2001, que Institui contribuições sociais, autoriza créditos de complementos de atualização monetária em contas vinculadas do Fundo de Garantia do Tempo de Serviço - FGTS e dá outras providências. O Inciso IV, por exemplo, "dispensa do pagamento das contribuições sociais instituídas pelos arts. $1^{\circ}$ e $2^{\circ}$ da Lei Complementar $\mathrm{n}^{\circ} 110$, de 29 de junho de 2001". Essas contribuições sociais referem-se ao pagamento da alíquota de $10 \%$ de FGTS ao trabalhador. Desta forma, a PLP traz uma grande vitória do capital sobre o trabalho, ao reduzir a carga que se agrega ao custo da força de trabalho. E, além disso, desprotege o trabalhador de demissões arbitrárias, que era justamente o objetivo da multa de $40 \%$ do FGTS. Com essa brecha, é óbvio que os empresários terão maiores estímulos para demitir os trabalhadores, podendo, com isso, oferecer pressão de todos os tipos sobre eles: horas extras, intensificação do trabalho, polivalência e multifuncionalidade, redução de salário e de outros benefícios.

\section{Considerações Finais}

Frente às questões apresentadas, sumariamente levantadas das propostas empresariais, podemos questionar: qual a verdadeira "pedagogia" que advém da CNI? Ela realmente coaduna com uma "educação de qualidade", como sempre se afirma nos documentos dessa instituição?

Claro está que, para além dos discursos educativos do empresariado, em que a cidadania, a qualidade na formação etc. são figuras constantes, na realidade o que se esconde é a pretensão, pelos empresários, de uma educação que adapte os trabalhadores ao precário cenário das relações de trabalho.

O conjunto das reformas apontadas no texto, sem dúvida, constitui um documento amplamente pedagógico, ou seja, é uma nítida demonstração de como o processo formativo ocorre no seio das relações de classe na sociedade.

Se, em um exercício mental, conseguíssemos montar um cenário plenamente vantajoso para o capital - cenário esse que, ademais, não seria tão fantasioso assim - poderíamos imaginar o perfil do trabalhador: um indivíduo que trabalha 44 horas semanais, em condições de alta competitividade industrial, cuja seguridade é mínima. Portanto, esse trabalhador pode estar na eminência de demissão a todo o momento, contando, nesse caso, apenas com um sistema bastante frágil de seguridade social.

Chamamos, assim, a atenção para o fato de que não se pode descolar a formação profissional das relações sociais mais amplas, e lembramos que os projetos educativos não existem apenas no papel, mas são formas sociais, ideológicas, de manifestação das lutas de classes.

Os dados empíricos aqui trazidos demonstram claramente como as lutas de classes ocorrem no seio da produção, momento predominante, ontológico, do ser social (LUKÁCS, 1979). Do ponto de vista da burguesia industrial, interessa a fragilização da classe oponente, o proletariado. E para essa classe, o que interessa? Qual o seu projeto de enfrentamento em relação a essa situação? E qual o papel da educação nesse cenário de lutas? Essas questões, entre outras, são de relevante importância para futuras discussões. 


\section{Referências}

BRASIL. Constituição (1988). Constituição da República Federativa do Brasil, de 05 de outubro de 1988. Disponível em: <http://www.planalto.gov.br/ccivil_03/constituicao/ constitui $\% \mathrm{C} 3 \% \mathrm{~A} 7 \mathrm{ao} . \mathrm{htm}>$. Vários acessos.

ALVES, G. Reestruturação produtiva, novas qualificações e empregabilidade. In: Dimensões da reestruturação produtiva: ensaios de sociologia do trabalho. Londrina: Práxis, 2007. Disponível em: <www.giovannialves.org>. Vários acessos.

ANTUNES, R. Adeus ao trabalho: ensaio sobre as metamorfoses e a centralidade do mundo do trabalho. 10.ed. São Paulo: Cortez; Ed. Unicamp, 2005.

CONFEDERAÇÃO NACIONAL DA INDÚSTRIA. A indústria e o Brasil: uma agenda para o crescimento. Brasília, 2002.

\section{Conclusões do $3^{\circ}$ Encontro Nacional da Indústria} 2008: recomendações e propostas. Brasília: CNI, 2008.

Convenção 158 da OIT: tema importante para as empresas e para o país. Brasília: CNI, 2008b. Disponível em: <www.cni.org.br>. Acesso em 19 jan. 2010.

CNI em ação: edição especial. Ano II, n.1. 18 dez. 2009a. Disponível em: <www.cni.org.br>. Vários acessos.

Informe legislativo. Ano 17, n. 28, 11 de novembro de 2009b. Disponível em: <www.cni.org.br/portal/lumis/ portal/file/fileDownload.jsp?fileId $>$. Acesso em 12 jan. 2010 .

Terceirização: sondagem especial, ano 7, n. 02, abril de 2009c. Disponível em: <www.cni.org.br>. Vários acessos.

Redução da jornada de trabalho: mitos e verdades. Brasília: CNI, 2009d. Disponível em: www.cni. org.br. Acesso em 19 jan. 2010.

DEPARTAMENTO INTERSINDICAL DE ESTATÍSTICA E ESTUDOS SOCIOECONÔMICOS. Reduzir a jornada de trabalho é gerar empregos de qualidade. Nota Técnica, n. 57, Novembro de 2007. Disponível em: <http://www. dieese.org.br/notatecnica/notatec57JornadaTrabalho.pdf $>$. Acesso em 05 de janeiro de 2010.

INSTITUTO DE ESTUDOS PARA O DESENVOLVIMENTO INDUSTRIAL. A diminuição da rotatividade do trabalho: sinal da modernização industrial? Carta

IEDI, n. 179. Publicada em 28 out. 2005. Disponível em: $<$ http://www.iedi.org.br/cgi/cgilua.exe/sys/start.htm?tpl= printerview\&sid=20\&infoid=1602> . Acesso em 15 março 2010 .

LUKÁCS, G. Ontologia do ser social: os princípios ontológicos fundamentais de Marx. São Paulo: L.E.C.H, 1979.
MARCELINO, P. R. P. Terceirização do Trabalho no Brasil e na França. In: SIMPÓSIO ESTADUAL LUTAS SOCIAIS NA AMÉRICA LATINA. CRISE DAS DEMOCRACIAS LATINO-AMERICANAS: DILEMAS E CONTRADIÇÕES, 2, 2006, Londrina. Anais... Disponível em: <http://www.uel.br/grupo-pesquisa/g e p a $1 /$ s e g u n d o g e p a 1/PA U L A \% 20 R E G I N A -\%20PEREIRA\%20 MARCELINO.pdf $>$. Acesso em 04 jan. 2010.

MARX, K.; ENGELS, F. A ideologia alemã. 4.ed. São Paulo: Hucitec, 1984.

PASTORE, J. Perspectivas e problemas do emprego no Brasil. Seminário Brasil-Canadá: desafios para a criação de empregos. Brasília, 2005. Disponível em: <www.cebri.org. br/pdf/232 pdf.pdf $>$. Acesso em 12 jan. 2010.

SAISSE, S. A regulação do trabalho no Brasil: obstáculo ao aumento da renda e do emprego. Brasília: CNI, 2005. (Nota Técnica CNI, n.4).

Enviado para publicação: 28/05/2012 Aceito para publicação: 20/07/2012 